\title{
Relationships between students' conceptions of constructivist learning and their regulation and processing strategies
}

\author{
Sofie M. M. Loyens · Remy M. J. P. Rikers $\cdot$ Henk G. Schmidt
}

Published online: 12 August 2008

(C) The Author(s) 2008. This article is published with open access at Springerlink.com

\begin{abstract}
The present study investigated relationships between students' conceptions of constructivist learning on the one hand, and their regulation and processing strategies on the other hand. Students in a constructivist, problem-based learning curriculum were questioned about their conceptions of knowledge construction and self-regulated learning, as well as their beliefs regarding their own (in)ability to learn and motivation to learn. Two hypothesized models were tested within 98 psychology students, using a structural equation modelling approach: The first model implemented regulation and processing variables of the Inventory of Learning Styles [ILS, Vermunt (Learning styles and regulation of learning in higher education - towards process-oriented instruction in autonomous thinking, 1992)], the second model of the Motivated Strategies for Learning Questionnaire [MSLQ, Pintrich and de Groot (Journal of Educational Psychology, 82, 33-40, 1990)]. Results showed that structural relations exist between conceptions of constructivist learning and regulation and processing strategies. Furthermore, students who express doubt with regard to their own learning capacities are at risk for adopting an inadequate regulation strategy. A three-tiered structure of conceptual, controlling, and operational level appeared valid for the MSLQ variables, but not entirely for those of the ILS.
\end{abstract}

Keywords Cognitive strategy use · Conceptions · Constructivism · ILS · MSLQ - Self-regulation

Education involves the interplay of learners, teachers, and learning environments. In contrast to a few decades ago, the learner has received a more central role. Students themselves decide to a larger extent what and how to learn and they actually need to take responsibility for their own learning in order to become more effective learners (e.g., Kuhn 2007). One view on learning that considers the learner as an active agent in the process of

S. M. M. Loyens $(\bowtie) \cdot$ R. M. J. P. Rikers · H. G. Schmidt

Department of Psychology, Erasmus University Rotterdam, Burg. Oudlaan 50, Rotterdam 3062 PA,

The Netherlands

e-mail: loyens@fsw.eur.nl 
knowledge acquisition is constructivism. Constructivism is an umbrella term for various views on learning (Gijbels et al. 2006), which focus on how learners create meaning and which argue that this knowledge construction process requires active engagement of the learner. A working definition of constructivism could be: A theory of how we learn, grounded in philosophy, that has led to the development of several educational applications (e.g., problem-based learning). Constructivism is, however, embodied in numerous ways (e.g., Windschitl 2002). Nevertheless, most views share four core features or constructs that should be considered while creating learning environments for students. These constructs can be labelled as (1) knowledge construction, (2) cooperative learning, (3) selfregulated learning, and (4) the use of meaningful, authentic problems in education (e.g., Driscoll 2005; Marshall 1992). In short, knowledge construction refers to the use of prior knowledge when new information is interpreted. Second, cooperative learning embodies the idea that social interaction and negotiation can help learners in their knowledge acquisition process. A third construct within constructivist learning, self-regulated learning, presupposes aspects such as goal-setting, metacognition, and self-assessment and is viewed as the key to successful learning. The use of meaningful problems in education, finally, refers to confronting students with complex, meaningful problems to make learning situations more similar to real-life, professional situations, which promotes transfer of knowledge (for a detailed discussion, see Loyens et al. 2007a). Constructivist learning environments have been rapidly embraced in areas of education (Tenenbaum et al. 2001). It has been argued that they promote motivation (e.g., Norman and Schmidt 1992). On the other hand, these learning environments require a great deal of responsibility from learners in terms of being socially apt, self-regulated knowledge constructors. Some learners may experience this as a positive challenge and as part of their learning process, but others may relapse into uncertainty, confusion, and even anxiety (Duke et al. 1998).

The emphasis of constructivist views on the learner as an active agent had an important implication: It brought personal knowledge constructions and learners' subjective beliefs to the fore in educational research (Wigfield et al. 1996), also referred to as "conceptions". A conception can be defined as "an individual's personal and therefore variable response to a specific idea" (Entwistle and Peterson 2004, p. 408). In the educational context, conceptions of learning can be described as "coherent systems of knowledge and beliefs about learning and related phenomena" (Vermunt and Vermetten 2004, p. 362). The more central role of the learner in education has caused that learners' conceptions with respect to learning received more attention. Therefore, conceptions of learning now constitute an important component of research on student learning (Vermunt 2007). The result is a large number of studies relating students' conceptions of knowledge (i.e., epistemologies) and conceptions of learning to other aspects of learning such as cognitive processing strategies (e.g., Vermunt 1996), regulation strategies (e.g., Purdie et al. 1996), motivation (e.g., Pintrich and Zusho 2002), and learning outcomes (e.g., McLean 2001). Those studies examined students' conceptions of learning, using existing taxonomies (e.g., qualitative categorisation by Marton et al. 1993) and focused on learning in general.

Besides ideas and beliefs about learning in general, students also have specific beliefs about the learning environment in which they are studying. Lowyck et al. (2004) have labelled these beliefs about the learning environment "instructional conceptions". More specifically, instructional conceptions are ideas about relationships between features of the learning environment and learning (Clarebout et al. 2007). The present study aims to investigate students' instructional conceptions of a constructivist learning environment. Little is known about students' conceptions of constructivist learning as well as relationships between these instructional conceptions and other components of learning such as 
regulation and processing strategies. Since constructivist views on learning assign a central role to the learner and presuppose that effective learning implies learners being socially apt, self-regulated knowledge constructors, it is important to investigate whether learners themselves perceive this in the same way. After all, as mentioned above, beliefs that students hold with respect to their responsibility in learning and what effective learning implies (i.e., students' conceptions of learning) show relationships with the actual learning activities (e.g., regulation and processing) that students undertake. Therefore, the present study was designed to shed light on the relationship between students' conceptions of constructivist learning and their regulation and processing strategies. It is examined whether these relations exist and if so, to what extent. In order to evaluate these connections, we first discuss studies on conceptions of constructivist learning as well as studies on conceptions of learning and regulation and processing strategies.

\section{Instructional conceptions of constructivist learning and learning variables}

The idea of instructional conceptions, which not only focus on learning or teaching as separate constructs, but specifically on the relationship between learning environment and learning, is fairly new in educational research and was only introduced in 2004 by Lowyck et al. (2004).

The same goes for research on students' beliefs about constructivist learning. Gijbels et al. 2006 compared students in a constructivist problem-based curriculum with students in a conventional learning environment regarding their perceptions of the instructional environment. They found that students in a problem-based learning environment perceived the presence of active construction of knowledge, conceptual conflicts, cooperative learning, and the student-centeredness of the curriculum more prevalently compared to students in a conventional learning environment.

With respect to relationships of students' conceptions of constructivist learning and other learning variables, a study by Loyens et al. (2007b) demonstrated significant relationships between conceptions of knowledge construction, self-perceived inability, and motivation to learn with self-study time and students' preparation for and participation in problem-based learning groups.

\section{Relationships between conceptions of learning and regulation and processing}

Studies relating conceptions of learning in general (mostly using the taxonomy of Marton et al. 1993) with students' regulation and processing are more established. Regulation and processing strategies are often summarized in the concept "study strategies" (Vermunt 1998). Processing can take place on a deep (i.e., relating ideas and seeking meaning) or surface (i.e., repetition and memorization) level (e.g., Entwistle and Peterson 2004). Regulation strategies steer the processing of information (Ferla et al. 2008) and can rely on the initiative of the learning him/herself or on external sources (e.g., teacher, chapter structure, etc.).

Van Rossum and Schenk (1984) studied the relationship between conceptions of learning, study strategies, and learning outcomes by letting participants study a text, followed by a questionnaire containing items about the text as well as items about their study strategy and conceptions of learning. They found that high quality learning outcomes are particularly related to learning conceptions that emphasize the constructive character of 
learning as well as deep processing. Crawford et al. (1994) came to the same conclusion in a study of student's conceptions of learning mathematics. Their research identified a structural relationship between students' conceptions of mathematics and their processing. Similarly, Dart et al. (2000) tested a structural model relating conceptions of learning and processing. They found that qualitative conceptions (such as 'learning is concerned with understanding and meaning by relating or connecting new material to prior knowledge') were particularly linked with deep processing. Furthermore, more advanced conceptions in which learning is seen as understanding instead of memorising, are found to be associated with a more frequent use of self-regulated learning strategies (Purdie et al. 1996). Ferla et al. 2008 tested a structural model in which conceptions of learning were related with regulation and processing strategies. Conceptions of learning showed significant relationships with both regulation and processing strategies.

In sum, several studies report relationships between conceptions of learning on the one hand and regulation and processing strategies on the other hand. Therefore, more and more studies in educational research examining student learning depart from an integrative approach, focussing on different aspects of learning and including students' conceptions as an important factor (e.g., Vermunt 2007).

Interestingly, measurement instruments of learning aspects also started to adopt this integrative approach. A prominent example in this respect is Vermunt's Inventory of Learning Styles (ILS; Vermunt 1992, 1998). The ILS measures four aspects of students' learning: Processing strategies, regulation strategies, mental models of knowledge (which can be labelled as conceptions of knowledge), and learning orientations (i.e., personal goals, intentions, motives, expectations, concerns, and doubts with respect to learning). Relationships among these four aspects are assumed and from a theoretical perspective, these aspects can be categorised into three levels. The first level is the cognitive-symbolic or conceptual level consisting of students' ideas and beliefs. Mental models of knowledge and learning orientations fall into this category. Furthermore, a controlling level can be distinguished that refers to regulation processes, whereas a third level, the operationalbehavioural level, concerns the processing strategies. The controlling level tunes the conceptual level to the operational level (Vermetten et al. 1999).

Another example of a measurement instrument combining students' beliefs and regulation and processing strategies is the Motivated Strategies for Learning Questionnaire (MSLQ, Pintrich and de Groot 1990). The MSLQ consists of three subscales: Cognitive strategy use, self-regulation, and motivational beliefs. Similar to the ILS, a three-tiered model could be assumed in which regulation strategies mediate the relationships between conceptions and processing strategies.

\section{The present study}

The present study also assumes an integrative approach and aims to investigate whether a relationship can be found between students' conceptions of constructivist learning on one hand, and regulation and processing strategies on the other hand. Furthermore, it is tested whether regulation strategies operate as mediating variables between conceptions and processing strategies.

As mentioned above, research on instructional conceptions is fairly new and little is known about instructional conceptions in the context of constructivist learning environments. This study is a first attempt to fill this gap. 
It is hypothesized based on previous research on conceptions of learning (e.g., Ferla et al. 2008; Purdie et al. 1996) that relationships exist between conceptions of constructivist learning and regulation and processing strategies, since previous research on conceptions of constructivist learning demonstrated relationships with learning activities such as self-study time and study preparation and participation (Loyens et al. 2007b). Furthermore, it is expected that conceptions of self-regulated learning show significant relationships with actual self-regulated learning activities. After all, students who agree on the significance of setting goals, planning, and monitoring one's progress are more likely to display these self-regulated learning activities. Due to the strong connections between selfregulated learning and motivation reported in educational research literature (e.g., Pintrich and Schunk 1996), we also expect significant relationships of the variable motivation to learn with regulation strategies. Finally, since self-perceived inability to learn has been mentioned as a possible negative consequence of constructivist learning environments (Duke et al. 1998), negative relationships were expected from this variable.

\section{Method}

\section{Participants}

Participants were 98 third-year and fourth-year psychology students (79 female, 19 male; mean age $=22.60, S D=3.59$ ) enrolled in a problem-based learning $(\mathrm{PBL})$ curriculum at Erasmus University Rotterdam, the Netherlands.

The learning environment in which the study took place

The psychology curriculum in this study applies a problem-based learning approach. Problem-based learning has its roots in constructivist learning theories. Students work in small groups on meaningful, authentic problems, under the guidance of a tutor (Barrows 1996). First, students discuss a problem and possible explanations or solutions are proposed. Since their prior knowledge of the problem-at-hand is limited, this discussion leads to the formulation of issues for further self-directed learning. Subsequently, students spend time studying literature relevant to the issues generated. After this period of self-study, students share their findings, elaborate on knowledge acquired, and have an opportunity to correct misconceptions (Hmelo-Silver 2004; Schmidt 1983 ). The academic year consists of eight consecutive courses of five weeks each.

Materials

\section{Measurement of students' conceptions}

Students' conceptions of constructivist activities were measured by means of a questionnaire (Loyens et al. 2007a). This questionnaire measures students' opinions on knowledge construction, cooperative learning, self-regulated learning, and the use of meaningful, authentic problems. In addition, the questionnaire focuses on students' conceptions of selfperceived inability to learn (i.e., feelings of doubt concerning one's own learning capacities) and motivation to learn. All statements need to be rated on a 7-point Likert-scale 
ranging from -3 (entirely disagree) to +3 (entirely agree), with 0 reflecting a neutral opinion towards a statement.

In this study, we focused on students' conceptions of knowledge construction and selfregulated learning, since these assumptions reflect students' individual learning activities and on self-perceived inability to learn and motivation to learn as possible influences on students' learning. Cooperative learning and the use of authentic problems were not taken into account in this study, since these factors refer to curriculum characteristics, which imply that students are automatically confronted with these activities in a constructivist learning environment. Since the focus of this study is on relationships with regulation and processing strategies, we chose to zoom in on the conceptions of constructivist learning activities students can deliberately undertake (i.e., knowledge construction and self-regulated learning) and on the conceptions of self-perceived inability to learn and motivation to learn as possible influences on students' learning.

The questionnaire used was influenced by research on self-regulated learning and motivation (Pintrich and de Groot 1990), mental models (Vermunt 1992), conceptions of learning (Marton et al. 1993), conceptions of knowledge (Schraw et al. 2002), and constructivist literature (e.g., Steffe and Gale 1995; Tenenbaum et al. 2001) with respect to its theoretical background. However, this questionnaire focuses explicitly on conceptions of constructivist learning activities and is therefore different from existing instruments. Examples of items are shown in Table 1.

Confirmatory factor analysis has demonstrated that the questionnaire was able to measure students' conceptions in a reliable and valid fashion. The reliability of the six latent constructs was assessed using coefficient H (Hancock and Mueller 2001) and ranged from .60 to .86 (Loyens et al. 2007a).

\section{Measurement of students' processing and regulation strategies}

Students' regulation and processing strategies were measured by Part A 'Study strategies' of Vermunt's ILS (Vermunt 1992). Three processing strategies are part of the ILS: Deep processing (characterized by relating and structuring and critical processing, $n=11$ items), stepwise processing (characterized by memorising and rehearsing and analysing, $n=11$ items), and concrete processing ( $n=5$ items). Furthermore, three regulation strategies are measured by this questionnaire: Self-regulation (both of learning process/ results and learning content, $n=11$ items), external regulation (both of learning process and learning results, $n=11$ items), and lack of regulation ( $n=6$ items). For each item, participants had to indicate on a 5-point Likert-scale to what extent the statement applied to them $(1=I$ do this seldom or never, $5=I$ do this almost always). Because we were

Table 1 Item examples of students' conceptions of constructivist learning activities

\begin{tabular}{ll}
\hline Conception & Item examples (translated from Dutch) \\
\hline $\begin{array}{l}\text { Knowledge construction } \\
(n=10)\end{array}$ & "Previous learned facts are the building blocks of new knowledge" \\
$\begin{array}{l}\text { Self-regulated learning } \\
(n=9)\end{array}$ & "Preparing a test is difficult when the teacher has not pointed out exactly \\
what has to be studied" (reversed scoring) \\
$\begin{array}{l}\text { Self-perceived inability to } \\
\text { learn }(n=12)\end{array}$ & "I doubt if I can complete this study successfully" \\
Motivation to learn $(n=8)$ & "I easily find the motivation to study" \\
\hline
\end{tabular}


particularly interested in the relationship of study strategies and students' conceptions of constructivist learning, part B of the ILS, 'Study motives and study views' (i.e., mental models of knowledge and learning orientations) was not considered in our study.

As a second measure of regulation and processing strategies, corresponding items of the Motivated Strategies for Learning Questionnaire (MSLQ; Pintrich and de Groot 1990) were selected. Items of the MSLQ-subscales 'Cognitive strategy use' and 'Self-regulation' were included. However, because the MSLQ was designed for high-school education, two items of the cognitive strategy use subscale, stressing homework (item 31) and mentioning the teacher (item 36) were deleted for our study with higher-education students. A total of 20 items of the MSLQ (11 items of the cognitive strategy subscale and 9 items of the selfregulation subscale) were used and had to be rated on a 7-point Likert-scale ranging from 1 (= not at all true for me) to 7 (= very true for me). The MSLQ-part measuring motivational beliefs was not administered because of the focus on students' conceptions of constructivist learning.

\section{Procedure}

All three questionnaires were electronically administered to the students at the beginning of the academic year. Students could fill out the questionnaires in their own time, at home or at campus. The questionnaires' instructions stated that there were no right or wrong answers to the items, all answers were correct as long as they reflected students' personal opinions. Students who took part in the study received a one hour research credit for their participation.

\section{Statistical analysis}

Responses to negatively stated items were reversed so that for all items the highest response score was indicative of a positive rating of each construct. Descriptive statistics were calculated for all subscales.

A structural equation modelling approach was adopted to test different models concerning the relationship between students' conceptions of constructivist learning and regulation and processing strategies. Hypothesized structural relationships among the variables were established and the structural models, depicted in Figs. 1 and 2, were tested. In these models, students' conceptions of knowledge construction, self-regulated learning, self-perceived inability to learn, and motivation to learn are observed variables at the conceptual level (Loyens et al. 2007a). In Fig. 1, regulation processes of the ILS (selfregulation, external regulation, and lack of regulation) are modelled on the controlling level and the ILS-processing strategies (deep, stepwise, and concrete processing) on the operational level.

For the model depicted in Fig. 2, the same three levels were modelled using the regulation and processing subscales of the MSLQ (Pintrich and de Groot 1990).

Maximum likelihood estimations were used for the estimation of the models' parameters. For the evaluation of the models presented in Figs. 1 and 2, two groups of fit indices, absolute and incremental, were selected.

In the present study, $\chi^{2}$, accompanied by degrees of freedom, sample size, and $p$-value, as well as the root mean square error of approximation (RMSEA, Steiger 1990) were used as absolute fit indices. $\chi^{2}$ has been the traditional statistic to test the closeness of fit between an observed and predicted covariance matrix. A small $\chi^{2}$ value, relative to the 


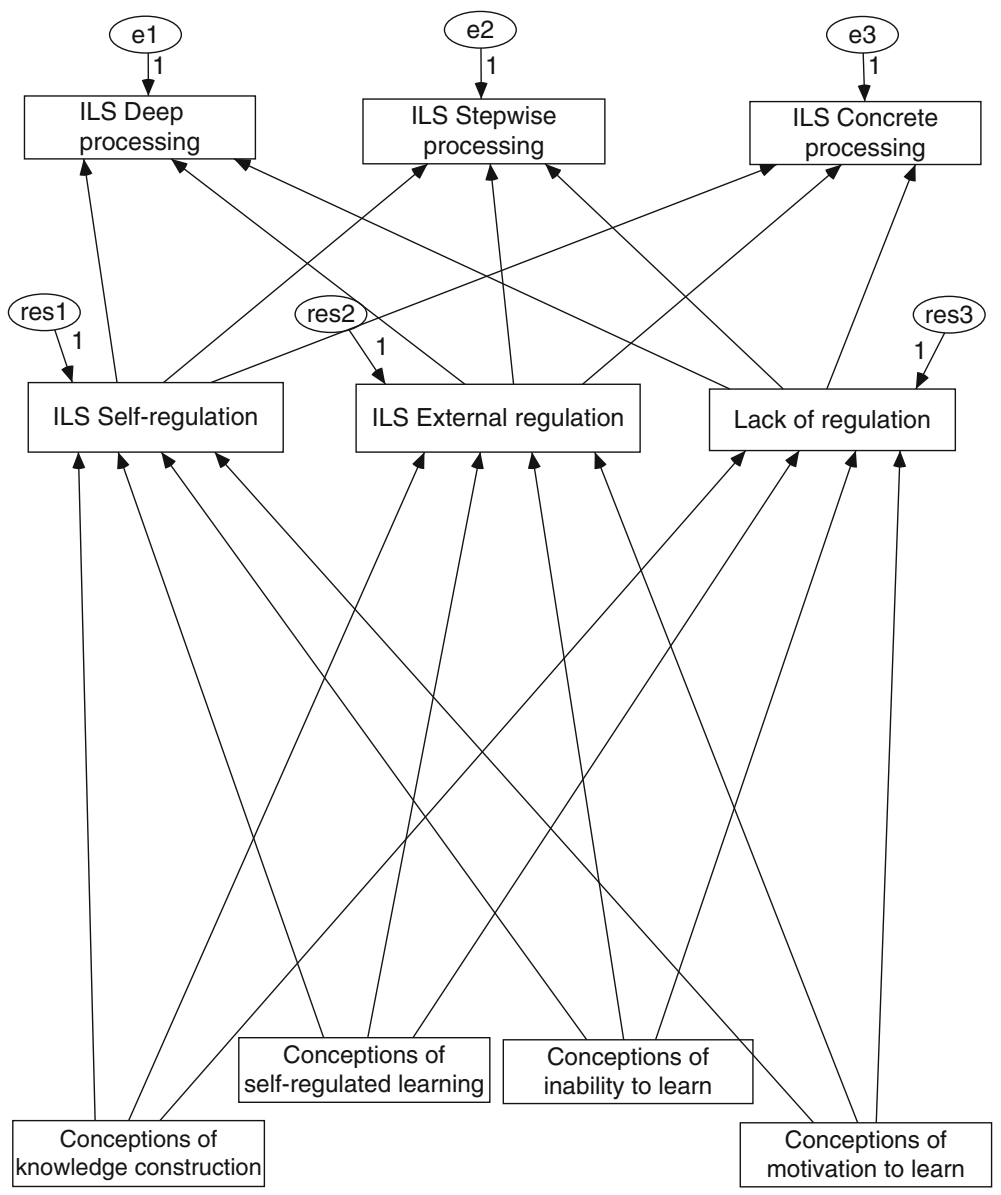

Fig. 1 Hypothesized model with ILS regulation and processing variables. Note: For clarity, correlations among the four conceptions of constructivist learning, among the residuals, and among the error terms were omitted

degrees of freedom, is an indication of good fit and vice versa (Byrne 2001). Although there is no clear-cut guideline about what value of $\chi^{2}$ divided by the model's degrees of freedom is minimally acceptable, it is frequently suggested that this ratio should be less than three (Kline 1998). RMSEA appears to be sensitive to model specification, minimally influenced by sample size, and not overly influenced by estimation method and was therefore included (Fan, Thompson and Wang 1999). The lower the value of RMSEA, the better the fit, with a cut-off value close to .06 (Hu and Bentler 1999).

Two incremental fit indices were included: The Tucker-Lewis index (TLI, Tucker and Lewis 1973) and the comparative fit index (CFI, Bentler 1990). Both indices range from zero to 1 , with higher values indicating a better fit. Values greater than .90 are traditionally associated with well-fitting models (Bentler 1990) although more recently, cut-off values close to .95 or .96 are suggested (Byrne 2001; Hu and Bentler 1999).

With respect to the values of the standardized path coefficients, values less than .10 indicate a small effect, values around .30 a medium effect, and values greater than $.50 \mathrm{a}$ large effect (Kline 1998). 


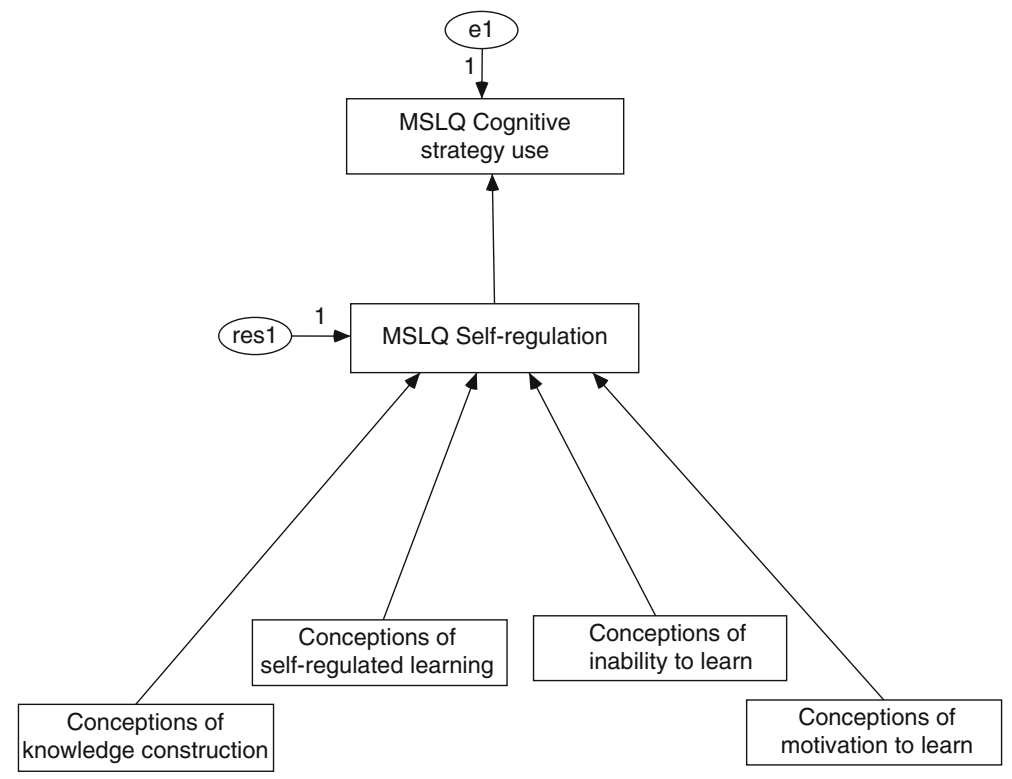

Fig. 2 Hypothesized model with MSLQ regulation and processing variables. Note: For clarity, correlations among the four conceptions of constructivist learning were omitted

Finally, $\Delta \chi^{2}$ tests were used to evaluate the three-level structure (i.e., the mediating role of the controlling level). Alternative hierarchical models of Figs. 1 and 2 were constructed with direct paths between the conception-variables and the processing strategies. Each $\Delta \chi^{2}$ statistic reflects the difference between the $\chi^{2}$ values of the two hierarchical models, its degrees of freedom equals the difference in the two models' degrees of freedom. A nonsignificant value of $\Delta \chi^{2}$ suggests that the overall fits of the two models are similar. With respect to the mediating, regulation variables, this implies that a completely mediated relation between students' conceptions and processing strategies by regulation activities is supported. A significant value of $\Delta \chi^{2}$ supports retention of the added paths and therefore implies a partially mediated relationship between the conceptual and operational level by the controlling level (Kline 1998).

Data were analyzed using Amos 7.0 (Arbuckle 2006).

\section{Results}

Descriptive analysis

Table 2 reports the means, standard deviations, sum scores, and correlations for each observed variable.

With respect to conceptions of constructivist learning, highest scores (i.e., factors on which students agreed the most) were obtained for conceptions of knowledge construction. For conceptions of self-regulated learning and inability to learn, mean scores were negative implying that students disagree with statements about self-regulated learning (although the negative score is close to zero) and that they do not report feelings of doubt concerning 


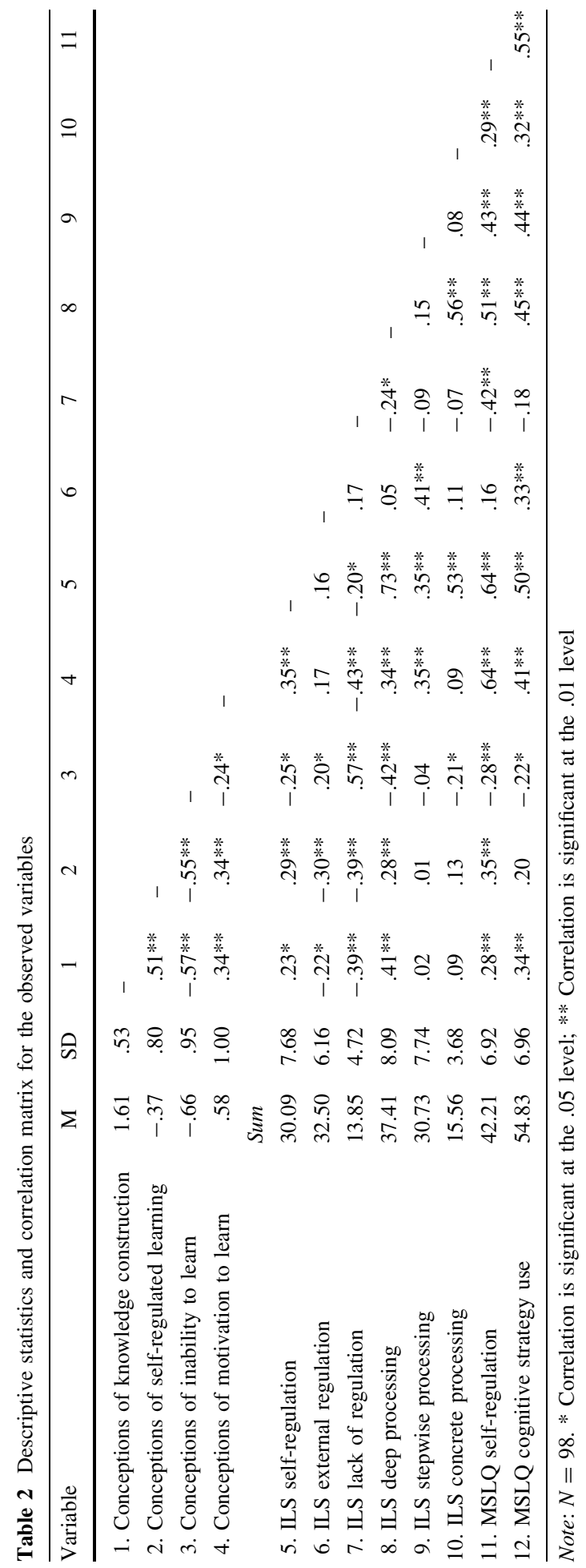


their learning processes. Except for the ILS self-regulation scores, students' mean scores on the subscales of the ILS were average compared to the ILS norm group of psychology students in higher education. Students' scores on the ILS self-regulation scale were slightly above average (Vermunt 1992).

Correlations among the four variables on the conceptual level were all significant and, as expected, conceptions of inability to learn showed negative relationships with all other variables, except with external regulation and lack of regulation. Similarly, lack of regulation showed negative correlations with all other variables, except for self-perceived inability to learn and external regulation. Conceptions were significantly correlated with constructivist learning activities such as self-regulation (of both ILS and MSLQ) and deep processing. However, for concrete processing and cognitive strategy use, not all relationships with students' conceptions were significant.

Concerning the ILS variables, self-regulation showed positive correlations with deep and concrete processing. This finding is in line with the defined learning styles of the ILS where self-regulation, deep, and concrete processing are all part of the meaning-directed learning style. Self-regulation also had a positive relationship with stepwise processing, but this correlation was less high compared to deep and concrete processing. External regulation on the other hand, showed a positive correlation with stepwise processing, which is in line with the reproduction-directed learning style that consists of both variables (Vermunt 1992).

The self-regulation subscale of the MSLQ showed the same pattern of correlations compared to the ILS self-regulation variable. The MSLQ cognitive strategy use variable, finally, showed positive correlations with self-regulation (of both ILS and MSLQ), external regulation, and all ILS processing variables as well as a negative, but not significant, correlation with lack of regulation.

Analysis of the structural model with regulation and processing variables of the ILS

Analysis of the hypothesized structural model depicted in Fig. $1(N=98)$ revealed a CFI of .97 a TLI of .88 , and a RMSEA of .09. These indices indicate a reasonable fit of the model with the data. The $\chi^{2}$ analysis, $\chi^{2}(12, N=98)=22.58, p>.01$, also suggested that the hypothesized model fits the data reasonably well. $\chi^{2}$ divided by the degrees of freedom of the hypothesized structural model depicted in Fig. 1 was less than two.

Table 3 displays estimates and standard errors of the structural parameters. Estimates displayed in Table 3 account for the hypothesized model that depict the relationships among students' conceptions of constructivist learning, regulation strategies, and students' processing strategies.

In total, nine regression paths were significant. With respect to students' conceptions of constructivist learning, conceptions of self-regulated learning, self-perceived inability to learn, and motivation to learn contributed significantly to the controlling level. Conceptions of self-regulated learning maintained a strong negative relationship with external regulation and a positive, although not significant, relationship with self-regulation. Conceptions of self-perceived inability to learn had a large positive relationship with lack of regulation. This implies that students who express high levels of doubt with regard to their learning process are at risk for adopting an inadequate regulation strategy. Conceptions of motivation to learn had a negative relationship with lack of regulation and positive relationships with self-regulation as well as external regulation. Conceptions of knowledge construction did not show any significant relationships with students' reported regulation strategies. 
Table 3 Estimates and standard errors of structural parameters for ILS variables

\begin{tabular}{|c|c|c|c|}
\hline Parameter & $\begin{array}{l}\text { Unstandardized } \\
\text { estimates }\end{array}$ & $\begin{array}{l}\text { Standardized } \\
\text { estimates }\end{array}$ & $\begin{array}{l}\text { Standard } \\
\text { error }\end{array}$ \\
\hline $\begin{array}{l}\text { Conceptions of knowledge construction } \rightarrow \text { ILS self- } \\
\text { regulation }\end{array}$ & .05 & .01 & 1.74 \\
\hline $\begin{array}{l}\text { Conceptions of self-regulated learning } \rightarrow \text { ILS self- } \\
\text { regulation }\end{array}$ & 1.27 & .13 & 1.14 \\
\hline $\begin{array}{l}\text { Conceptions of inability to learn } \rightarrow \text { ILS self- } \\
\text { regulation }\end{array}$ & -.88 & -.11 & .99 \\
\hline $\begin{array}{l}\text { Conceptions of motivation to learn } \rightarrow \text { ILS self- } \\
\text { regulation }\end{array}$ & $2.17 * *$ & .28 & .77 \\
\hline $\begin{array}{l}\text { Conceptions of knowledge construction } \rightarrow \text { ILS } \\
\text { external regulation }\end{array}$ & -1.80 & -.16 & 1.37 \\
\hline $\begin{array}{l}\text { Conceptions of self-regulated learning } \rightarrow \text { ILS } \\
\text { external regulation }\end{array}$ & $-2.52 * *$ & -.33 & .90 \\
\hline $\begin{array}{l}\text { Conceptions of inability to learn } \rightarrow \text { ILS external } \\
\text { regulation }\end{array}$ & .01 & .02 & .78 \\
\hline $\begin{array}{l}\text { Conceptions of motivation to learn } \rightarrow \text { ILS external } \\
\text { regulation }\end{array}$ & $2.08 * *$ & .34 & 61 \\
\hline $\begin{array}{l}\text { Conceptions of knowledge construction } \rightarrow \text { ILS lack } \\
\text { of regulation }\end{array}$ & .10 & .01 & .89 \\
\hline $\begin{array}{l}\text { Conceptions of self-regulated learning } \rightarrow \text { ILS lack } \\
\text { of regulation }\end{array}$ & -.11 & -.02 & .58 \\
\hline $\begin{array}{l}\text { Conceptions of inability to learn } \rightarrow \text { ILS lack of } \\
\text { regulation }\end{array}$ & $2.46 * *$ & .49 & .51 \\
\hline $\begin{array}{l}\text { Conceptions of motivation to learn } \rightarrow \text { ILS lack of } \\
\text { regulation }\end{array}$ & $-1.48 * *$ & -.31 & .40 \\
\hline ILS self-regulation $\rightarrow$ ILS deep processing & $.76^{* *}$ & .72 & .08 \\
\hline ILS self-regulation $\rightarrow$ ILS stepwise processing & $.27 * *$ & .27 & .09 \\
\hline ILS self-regulation $\rightarrow$ ILS concrete processing & $.26^{* *}$ & .54 & .04 \\
\hline ILS external regulation $\rightarrow$ ILS deep processing & -.07 & -.05 & .09 \\
\hline ILS external regulation $\rightarrow$ ILS stepwise processing & $.48^{* *}$ & .38 & .11 \\
\hline ILS external regulation $\rightarrow$ ILS concrete processing & .01 & .02 & .05 \\
\hline ILS lack of regulation $\rightarrow$ ILS deep processing & -.13 & -.08 & .12 \\
\hline ILS lack of regulation $\rightarrow$ ILS stepwise processing & -.16 & -.10 & .15 \\
\hline ILS lack of regulation $\rightarrow$ ILS concrete processing & .03 & .04 & .07 \\
\hline
\end{tabular}

Note: $* * p<.01$

Furthermore, several path coefficients from the controlling to the operational level were significant. Self-regulation had a very strong relationship with deep processing, a strong relationship with concrete processing, as well as a relationship with stepwise processing. External regulation had a fairly large relationship with stepwise processing and no significant relationships with deep and concrete processing. Lack of regulation, finally, did not show significant path estimates with the operational level variables.

$\Delta \chi^{2}$ test for the structural model with regulation and processing variables of the ILS

Finally, a model assuming direct paths from students' conceptions to processing strategies was compared with the hypothesized model as suggested by Fig. 1. This was done to 
Table 4 Estimates and standard errors of structural parameters for MSLQ variables

\begin{tabular}{lccc}
\hline Parameter & $\begin{array}{l}\text { Unstandardized } \\
\text { estimates }\end{array}$ & $\begin{array}{l}\text { Standardized } \\
\text { estimates }\end{array}$ & $\begin{array}{l}\text { Standard } \\
\text { Error }\end{array}$ \\
\hline $\begin{array}{l}\text { Conceptions of knowledge construction } \rightarrow \text { MSLQ } \\
\text { self-regulation }\end{array}$ & .30 & .02 & 1.28 \\
$\begin{array}{l}\text { Conceptions of self-regulated learning } \rightarrow \text { MSLQ } \\
\text { self-regulation }\end{array}$ & .98 & .11 & .84 \\
$\begin{array}{l}\text { Conceptions of inability to learn } \rightarrow \text { MSLQ self- } \\
\text { regulation }\end{array}$ & -.63 & -.09 & .71 \\
$\begin{array}{l}\text { Conceptions of motivation to learn } \rightarrow \text { MSLQ self- } \\
\text { regulation }\end{array}$ & $4.09 * *$ & .59 & .57 \\
$\begin{array}{l}\text { MSLQ self-regulation } \rightarrow \text { MSLQ cognitive strategy } \\
\text { use }\end{array}$ & $.55^{* *}$ & .55 & .09 \\
\hline
\end{tabular}

Note: $* * p<.01$

examine whether relations between students' conceptions and the operational level are completely mediated by students' regulation strategies. This alternative model was identical to the model in Fig. 1, but it assumed additional paths from the conceptions directly to all three processing variables. This alternative model resulted in a saturated model with 0 degrees of freedom. Therefore, the $\chi^{2}$ test of the model depicted in Fig. 1 also serves as the $\Delta \chi^{2}$ test since the saturated model has, by default, a $\chi^{2}$ of zero. The value of $\Delta \chi^{2}$ $(d f=12)=22.58$, was significant at the .05 level, assuming partial mediation. In other words, adding direct relations between conceptions and processing variables lead to a better explanation of the data compared to complete mediation.

Therefore, relations between conceptions and the endogenous factors at the operational level are only partially mediated by students' reported regulation strategies. The regression coefficients of the alternative model showed a significant $(p<.001)$, negative relationship between self-perceived inability to learn and deep processing (unstandardized regression weight $=-3.00$; standardized regression weight $=-.35$; standard error $=.80$ ). No other variables at the conceptual level showed significant, direct connections with the operational level. When the model depicted in Fig. 1 was rerun with a direct path from self-perceived inability to deep processing, the following fit measures were obtained: $\chi^{2}(11$, $N=98)=13.38, p>.10, \mathrm{CFI}=.99$, TLI $=.97$, RMSEA $=.05$. It should be noted, however, that in order to draw reliable conclusions, this renewed model should be tested in a new, independent sample.

Analysis of the structural model regulation and processing variables of the MSLQ

Testing the hypothesized structural model with the regulation and processing variables of the MSLQ resulted in a CFI of .99 a TLI of .95 , and a RMSEA $=.08$ indicating a good fit with the data. The $\chi^{2}$ analysis, $\chi^{2}(4, N=98)=6.40, p>.10$, also supported good model fit.

Table 4 shows the estimates and standard errors of the structural parameters of the hypothesized model with the MSLQ-variables.

The estimates shown in Table 4 revealed two significant path estimates. On the conceptual level, motivation to learn had a strong relationship with self-regulation. The path coefficient from conceptions of self-regulated learning to reported self-regulation on the 
controlling level was not significant. No other conceptions of constructivist learning had significant relationships with self-regulation.

Self-regulation strategies had strong relationships with cognitive strategy use, in line with the data of the ILS variables.

$\Delta \chi^{2}$ test for the structural model with regulation and processing variables of the MSLQ

Again, including direct paths from the conceptions to the processing-variable resulted in a just-identified or saturated model with zero degrees of freedom. Therefore, the value of the $\chi^{2}$ test of the model depicted in Fig. 2 is also the value of the $\Delta \chi^{2}$ test; $\Delta \chi^{2}(d f=4)=6.40$. This result is nonsignificant at the .05 level, indicating that direct relations between conceptions and cognitive strategy use did not lead to a better explanation of the data. Therefore, any relations between conceptions and the endogenous factor (i.e., cognitive strategy use) are entirely mediated by self-regulation. However, in this model, the direct path from conceptions of knowledge construction to cognitive strategy use was significant (unstandardized regression weight $=3.10$; standardized regression weight $=.24$; standard error $=1.39)$.

\section{Discussion}

Relationships between conceptions of constructivist learning and regulation and processing strategies

The present study investigated relationships between students' conceptions of constructivist learning on the one hand, and their regulation and processing strategies on the other hand. Students in a constructivist, problem-based learning curriculum were questioned about their beliefs about the utility of knowledge construction and self-regulated learning. In addition, their beliefs about their own (in)ability to learn and motivation to learn were studied. Two hypothesized models were tested and a $\Delta \chi^{2}$ test was used to examine whether relationships between students' conceptions and processing strategies were mediated by students' self-regulated learning activities. The first model implemented regulation and processing variables of the ILS, the second model of the MSLQ. Results revealed a reasonable fit of the ILS model with the data. Previous studies have shown mixed results with regard to model fit of all ILS variables tested in a hypothesized structural model (e.g., Boyle et al. 2003; Vermetten et al. 1999). An explanation could lie in the partially mediated relationships, which will be discussed later on. Testing the second hypothesized model with regulation and processing variables of the MSLQ resulted in a good fit. Altogether, these findings imply that structural relations exist between instructional conceptions of a constructivist learning environment and regulation and processing strategies.

The pattern of path coefficients

Students' conceptions of inability to learn showed strong relationships with lack of regulation. This implies that students who report feelings of doubt with regard to their learning process are likely to adopt an inadequate regulation strategy. As hypothesized, this factor is detrimental for students' learning. Earlier research, however, has demonstrated that conceptions of inability to learn had positive relationships with students' self-study time 
(Loyens et al. 2007b). It has been argued that students' encounter with their perceived inability is not necessarily harmful for their learning processes. Possibly, they will work harder to manage this uncertainty and by doing so, they may come to a degree of acceptance or tolerance of uncertainty, which makes them less averse to it (Block 1996). Nevertheless, the present findings suggest that extra study hours of these students do not necessarily lead to more effective study strategies. On the contrary, these students are likely to adopt an undirected regulation strategy. Because an undirected learning style (which consists of a lack of regulation) has been proven to be consistently and negatively related to study outcomes (Vermunt and Vermetten 2004), students' expressing self-perceived inability to learn are at risk.

The negative relationship between conceptions of motivation to learn and lack of regulation could be expected. Students who indicate to agree with statements such as "I can easily find the motivation to study" are not likely to adopt an undirected regulation strategy. As hypothesized, conceptions of motivation had significant relationships with the ILS self-regulation variable as well as the MSLQ self-regulation variable. More striking, however, is the relationship between conceptions of motivation and external regulation. The issue that comes to mind in this respect is the dichotomy intrinsic versus extrinsic motivation. However, this dichotomy was not as such integrated in the factor structure of the motivation to learn-variable, meaning that motivational aspects such as study goals (i.e., learning versus performance goals) were not explicitly questioned. It could be argued that some students can obtain high scores on statements such as "I can easily find the motivation to study" because they have high grades in mind (performance goals) and not because they are intrinsically motivated in the subject matter (learning goals). Using a more specific measure of motivation could shed light on this issue in future research.

Conceptions of self-regulated learning had small, but not significant, relationships with actual reported self-regulation activities. Mean scores on conceptions of self-regulated learning revealed that in general, students tend to disagree with this construct, implying that they prefer that the teacher directs their learning and indicates what main and side issues are in the subject matter. However, the student population in this study did report use of self-regulated learning activities, even slightly above average compared to a norm group of psychology students (Vermunt 1992). Winne (1995) has argued that all learners are inevitably engaged in self-regulated learning activities (i.e., they all plan and monitor to some degree). Nevertheless, Table 2 showed that students who believe that self-regulation is beneficial for their learning are more likely to engage in self-regulated behaviour. Students who agree with the benefits of self-regulated learning, however, do not believe that external regulation is of use for their learning. In terms of implications, more attention should be given to those students who entirely disagree that aspects of self-regulation such as goal setting, self-observation, self-assessment, and self-reinforcement can be helpful for their learning process, because differences in self-regulated strategy use reflect on academic achievement (e.g., Cantwell and Moore 1996; VanZile-Tamsen and Livingston 1999).

In both hypothesized models, conceptions of knowledge construction did not show significant relationships with regulation strategies, while these conceptions significantly predict students' learning activities as observed by their tutors in earlier research (Loyens et al. 2007b). One could argue that these conceptions would primarily have relationships with cognitive processing strategies, since the knowledge construction variable consists of processing concepts such as elaboration and an active processing of the subject matter. However, direct paths from the knowledge construction-variable to the operational level 
could only be observed in the model with the MSLQ variables, but not in the model with the ILS variables.

Path coefficients between the controlling and operational level were in line with previous findings. For the model depicted in Fig. 1, results were in line with defined learning styles as outlined in the Results-section. However, self-regulation showed a moderate relationship with stepwise processing, while the latter is part of a reproduction-oriented learning style. The combination of self-regulation with stepwise processing has been shown to lead to low performances of students (Beishuizen et al. 1994). On the other hand, deep processing does not completely exclude stepwise processing. Entwistle and Peterson (2004) state that memorisation may be acquired at some stage of the learning process, for certain purposes or in certain subject areas. Memorisation can precede understanding. Our results do confirm that self-regulation leads to deep and concrete processing, but it can also lead to stepwise processing.

\section{Mediated relationship between conceptual and operational level}

The $\Delta \chi^{2}$ tests showed different results for both hypothesized models. For the ILS, partial mediation is supported. A strong, negative relationship between self-perceived inability to learn and deep processing could be derived from the saturated model, although the reliability of this finding needs to be explored in a new, independent sample. The result is in line with earlier findings of Vermetten et al. (1999). They concluded that regulation strategies do function on a controlling level, but these strategies are not strict mediators. The present results seem to confirm this role of regulation strategies for the ILS model.

With respect to the MSLQ variables, complete mediation of self-regulation was found, implying that the influence of the conceptual level on the operational level is completely controlled by self-regulation. To our knowledge, no previous studies have tested this threelevel structure on the MSLQ. The important, controlling role of self-regulation for this instrument became apparent in this study. It would be interesting to investigate whether the model depicted in Fig. 2 also holds with the conceptual variables of the MSLQ (i.e., motivational beliefs subscale).

\section{Limitations}

There is a constraint to our findings. The sample size used in this study $(N=98)$ is rather small. However, the hypothesized models tested in our study are rather simple (i.e., do not consist of a large number of parameters) which is another important consideration that needs to be taken into account (Kline 1998).

Another constraint is the fact that self-regulation and processing strategies were selfreport measures. Although self-report measures are frequently used in educational research studies, there is a need for more behavioural measures.

Finally, this study was conducted with third- and fourth year students. This student population was chosen because they have gained quite some experience with regulating their study activities and finding effective processing strategies. Future research should test the proposed models with other student populations to examine generalizibility.

Acknowledgements The authors gratefully acknowledge Prof. Dr. Gregory Hancock of the University of Maryland for his invaluable suggestions with regard to the statistical analyses. Also, we would like to thank Vereniging Trustfonds Rotterdam for their financial support. 
Open Access This article is distributed under the terms of the Creative Commons Attribution Noncommercial License which permits any noncommercial use, distribution, and reproduction in any medium, provided the original author(s) and source are credited.

\section{References}

Arbuckle, J. L. (2006). Amos 7.0 user's guide. Chicago: SPSS.

Barrows, H. S. (1996). Problem-based learning in medicine and beyond: A brief overview. In W. H. Gijselaers (Ed.), New directions for teaching and learning (Vol. 68, pp. 3-11). San Francisco, CA: Jossey-Bass.

Beishuizen, J., Stoutjesdijk, E., \& Van Putten, K. (1994). Studying textbooks: Effects of learning styles, study task, and instruction. Learning and Instruction, 4, 151-174.

Bentler, P. M. (1990). Comparative fix indexes in structural models. Psychological Bulletin, 107, $238-246$.

Block, S. D. (1996). Using problem-based learning to enhance the psychosocial competence of medical students. Academic Psychiatry, 20, 65-75.

Boyle, E. A., Duffy, T., \& Dunleavy, K. (2003). Learning styles and academic outcome: The validity and utility of Vermunt's inventory of learning styles in a British higher education setting. British Journal of Educational Psychology, 73, 267-290.

Byrne, B. M. (2001). Structural equation modeling with AMOS: Basic concepts, applications, and programming. Mahwah, NJ: Erlbaum.

Cantwell, R. H., \& Moore, P. J. (1996). The development of measures of individual differences in selfregulatory control and their relationship to academic performance. Contemporary Educational Psychology, 21, 500-517.

Clarebout, G., Elen, J., Leonard, R., \& Lowyck, J. (2007). Assessing instructional conceptions: A task-based approach. Educational Research and Evaluation, 13, 109-125.

Crawford, K., Gordon, S., Nicholas, J., \& Prosser, M. (1994). Conceptions of mathematics and how it is learned: The perspectives of students entering university. Learning and Instruction, 4, 331-345.

Dart, B. C., Burnett, P. C., Purdie, N., Boulton-Lewis, G., Campbell, J., \& Smith, D. (2000). Students' conceptions of learning, the classroom environment, and approaches to learning. Journal of Educational Research, 93, 262-270.

Driscoll, M. (2005). Psychology of learning for instruction. Needham Heights, MA: Allyn \& Bacon.

Duke, M., Forbes, H., Hunter, S., \& Prosser, M. (1998). Problem-based learning (PBL): Conceptions and approaches of undergraduate students of nursing. Advances in Health Sciences Education, 3, 59-70.

Entwistle, N. J., \& Peterson, E. R. (2004). Conceptions of learning and knowledge in higher education: Relationships with study behaviour and influences of learning environments. International Journal of Educational research, 41, 407-428.

Fan, X., Thompson, B., \& Wang, L. (1999). Effects of sample size, estimation methods, and model specification on structural equation modeling fit indexes. Structural Equation Modeling, 6, 56-83.

Ferla, J., Valcke, M., \& Schuyten, G. (2008). Relationships between student cognitions and their effects on study strategies. Learning and Individual Differences, 18, 271-278.

Gijbels, D., van de Watering, G., Dochy, F., \& van den Bossche, P. (2006). New learning environments and constructivism: The students' perspective. Instructional Science, 34, 213-226.

Hancock, G. R., \& Mueller, R. O. (2001). Rethinking construct reliability within latent systems. In R. Cudeck, S. du Toit \& D. Sörbom (Eds.), Structural equation modeling: Present and future-a Festschrift in honor of Karl Jöreskog (pp. 195-216). Lincolnwood, IL: Scientific Software International.

Hmelo-Silver, C. E. (2004). Problem-based learning: What and how do students learn? Educational Psychology Review, 16, 235-266.

Hu, L., \& Bentler, P. M. (1999). Cutoff criteria for fit indexes in covariance structure analysis: Conventional criteria versus new alternatives. Structural Equation Modeling, 6, 1-55.

Kline, R. B. (1998). Principles and practice of structural equation modeling. New York: Guilford Press.

Kuhn, D. (2007). Is direct instruction an answer to the right question? Educational Psychologist, 42, 109-113.

Lowyck, J., Elen, J., \& Clarebout, G. (2004). Instructional conceptions: A prospective analysis. International Journal of Educational Research, 41, 429-444.

Loyens, S. M. M., Rikers, R. M. J. P., \& Schmidt, H. G. (2007a). Students' conceptions of distinct constructivist assumptions. European Journal of Psychology of Education, 12, 179-199.

Loyens, S. M. M., Rikers, R. M. J. P., \& Schmidt, H. G. (2007b). The impact of students' conceptions of constructivist assumptions on academic achievement and dropout. Studies in Higher Education, 32, 581-602. 
Marshall, H. H. (Ed.). (1992). Redefining student learning: Roots of educational change. Norwood, NJ: Ablex.

Marton, F., Dall'Alba, G., \& Beaty, E. (1993). Conceptions of learning. International Journal of Educational Research, 19, 277-300.

McLean, M. (2001). Can we relate conceptions of learning to student academic achievement? Teaching in Higher Education, 6, 399-413.

Norman, G. R., \& Schmidt, H. G. (1992). The psychological basis of problem-based learning: A review of the evidence. Academic Medicine, 67, 557-565.

Pintrich, P. R., \& de Groot, E. V. (1990). Motivational and self-regulated learning components of classroom academic performance. Journal of Educational Psychology, 82, 33-40.

Pintrich, P. R., \& Schunk, D. H. (1996). Motivation in Education. Theory, research, and applications. Englewoods Cliffs, NJ: Prentice-Hall.

Pintrich, P. R., \& Zusho, A. (2002). The development of academic self-regulation: The role of cognitive and motivational factors. In A. Wigfield \& J. S. Eccles (Eds.), Development of achievement motivation (pp. 250-284). San Diego, CA: Academic Press.

Purdie, N., Hattie, J., \& Douglas, G. (1996). Student conceptions of learning and their use of self-regulated learning strategies: A cross-cultural comparison. Journal of Educational Psychology, 88, 87-100.

Schmidt, H. G. (1983). Problem-based learning: Rationale and description. Medical Education, 17, 11-16.

Schraw, G., Bendixen, L. D., \& Dunkle, M. E. (2002). Development and validation of the Epistemic Belief Inventory (EBI). In P. R. Pintrich \& B. K. Hofer (Eds.), Personal epistemology: The psychology of beliefs about knowledge and knowing (pp. 261-275). Mahwah, NJ: Lawrence Erlbaum Associates, Publishers.

Steffe, L. P., \& Gale, J. E. (1995). Constructivism in education. Hillsdale, NJ: Erlbaum.

Steiger, J. H. (1990). Structural model evaluation and modification: An interval estimation approach. Multivariate Behavioral Research, 25, 173-180.

Tenenbaum, G., Naidu, S., Jegede, O., \& Austin, J. (2001). Constructivist pedagogy in conventional on-campus and distance learning practice: An exploratory investigation. Learning and Instruction, 11, 87-111.

Tucker, L. R., \& Lewis, C. (1973). A reliability coefficient for maximum likelihood factor analysis. Psychometrika, 38, 1-10.

Van Rossum, E. J., \& Schenk, S. M. (1984). The relationship between learning conception, study strategy and learning outcome. British Journal of Educational Psychology, 54, 73-83.

VanZile-Tamsen, C., \& Livingston, J. A. (1999). The differential impact of motivation on the self-regulated strategy use of high- and low-achieving college students. Journal of College Student Development, 40, 54-60.

Vermetten, Y. J., Lodewijks, H. G., \& Vermunt, J. D. (1999). Een structureel model over de relaties tussen leeropvattingen, regulatie en cognitieve verwerking [A structural model of the relationships among learning conceptions, regulation, and cognitive processing]. Tijdschrift voor Onderwijsresearch, 24, 8-20.

Vermunt, J. D. H. M. (1992). Leerstijlen en sturen van leerprocessen in het hoger onderwijs - naar procesgerichte instructie in zelfstandig denken [Learning styles and regulation of learning in higher education - towards process-oriented instruction in autonomous thinking]. Amsterdam/Lisse: Swets \& Zeitlinger.

Vermunt, J. D. (1996). Metacognitive, cognitive and affective aspects of learning styles and strategies, a phenomenographic analysis. Higher Education, 17, 647-682.

Vermunt, J. D. (1998). The regulation of constructive learning processes. British Journal of Educational Psychology, 68, 149-171.

Vermunt, J. D. (2007). The power of teaching-learning environments to influence student learning. In P. Tomlinson \& N. Entwistle (Eds.), Student learning and university teaching (pp. 73-90). Leicester, England: British Psychological Society.

Vermunt, J. D., \& Vermetten, Y. J. (2004). Patterns in student learning: Relationships between learning strategies, conceptions of learning, and learning orientations. Educational Psychology Review, 16, 359-384.

Wigfield, A., Eccles, J. S., \& Pintrich, P. R. (1996). Development between the ages of 11 and 25. In R. C. Calfee \& D. C. Berliner (Eds.), Handbook of educational psychology (pp. 148-185). New York: Macmillan.

Windschitl, M. (2002). Framing constructivism in practice as the negotiation of dilemmas: An analysis of the conceptual, pedagogical, cultural, and political challenges facing teachers. Review of Educational Research, 72, 131-175.

Winne, P. H. (1995). Self-regulation is ubiquitous but its forms may vary with knowledge. Educational Psychologist, 30, 217-221. 